\title{
Somente rastros na Areia: Foucault, Kant E A QUESTÃo (FILOSÓFICA) DA ANTROPOLOGIA
}

\begin{abstract}
SARDinha, Diogo (org.). ReVUe Rue Descartes (dossiê Kant/Michel Foucault et le ReNouveau de la PHilosophie antropologique), 2012/3, $\mathrm{N}^{\mathrm{o}}$ 75: 1-125.
\end{abstract}

\author{
Marcos Nalli ${ }^{1}$ \\ Tiaraju Dal Pozzo Pez²
}

As coletâneas não são concebidas para reunir pensadores diversos em torno de uma temática, mas fundamentalmente para, a partir dessa diversidade de autores em torno de uma unidade temática, fazer com que nós, leitores, exerçamos uma experiência de pensamento. A nosso ver, foi dessa forma que foi concebida a coletânea, publicada em 2012 (e que agora propomos apresentar aqui), pela revista francesa Rue Descartes, cujo tema versa sobre Kant, Foucault e a renovação da antropologia filosófica, e organizada por Diogo Sardinha, do Collège International de Philosophie.

As últimas linhas de As Palavras e as Coisas (1966) anunciam uma aposta na qual está lançada a suspeita do desaparecimento de uma invenção recente (o homem) numa imagem de/na areia - "[...] então se pode apostar que o homem se desvaneceria, como, na orla do mar, um rosto de areia." (FOUCAULT, 1992, p. 404). Apesar de essa passagem ter sido reduzida à polêmica humanística sobre a "morte do homem", parece-nos que ela se refere muito mais ao terreno (a areia do mar), na qual a imagem do homem foi

\footnotetext{
${ }^{1}$ Professor do Departamento de Filosofia e do Mestrado em Filosofia da Universidade Estadual de Londrina. E-mail: marcosnalli@yahoo.com. O presente texto é parte do projeto de pesquisa "Cura e terapêutica em Michel Foucault: psicopatologia, medicina e biopolítica" - Aprovado pelo CNPq (Processo 400544/2011-3).

${ }^{2}$ Doutorando em Filosofia pela Pontifícia Universidade Católica do Paraná - Curitiba.
} 
produzida. Trata-se da referência a um espaço, as "disposiçóes fundamentais do saber" (FOUCAULT, 1992, p. 404), que, na modernidade, tornou possível a forma homem, cuja reconfiguração fez com que ela fosse análoga a uma marca na areia. Nessa perspectiva, o desaparecimento anunciado náo opera uma morte, mas antes um des-locamento e um des-manchamento, pois o texto foucaultiano afirma ser o homem uma posição variável dependente da acomodação gerada pelos ventos e pelas ondas do mar, nos pequenos grãos de areia, ou seja, efeito das relaçóes que constituem o solo do saber. Este, não por acaso, é de areia, o que faz da posição-homem uma abertura num contínuo devir-outro, pois constantemente afetada pelas forças cósmicas que a perpassam. Assim, Foucault poderia ter dito - "tudo que é sólido desmancha no mar", pois o desaparecimento não é uma morte, mas um golpe antropológico, no qual o homem -como o castelo feito por uma criança na praia - é desmanchado à noitinha pela força da maré e, justamente por isso, há a possibilidade, com alegria juvenil, na manhá seguinte, de construí-lo novamente.

O pensamento foucaultiano abre-se para um devir criança, na medida em que aceita a areia como o local do jogo e o refazer, num começar novo, como sua regra imanente. Nesse sentido, o desaparecimento anunciado não é negativo, mas, ao contrário, afirmativo, pois é nesse campo aberto, como simples rastros na areia para ambos os lados do ponto onde estamos, que podemos "pensar o pensamento", que "[...] ainda há sentido, em filosofia, de falar em antropologia”, como observa Diogo Sardinha, na apresentação geral da revista Rue Descartes, publicada em 2012, número 75, dedicado à relação entre Kant e Foucault e sua pertinência para a discussão antropológica atual. Certamente, um dos fatores, ainda que não exclusivo, para a edição desse número especial da Rue Descartes se deve ao fato de que, em 2008, foi publicado pela primeira vez a introdução que Foucault escreve à tradução que fizera do Antropologia do Ponto de Vista Pragmático, de Immanuel Kant. Tratase de recepcionar, como numa manhá de festa, esse texto foucaultiano que ficara à margem por mais de quarenta anos, pois, como é sabido, a tradução e a introdução correspondem à tese secundária de Michel Foucault, apresentada por ocasião de seu doutoramento, em 1961. Enquanto seu História da Loucura (1961) veio a lume inicialmente pela casa editorial Plon e, a partir de 1972, pela Gallimard, de sua tese secundária apenas a tradução do texto de Kant foi publicado, pela Editora Vrin, sendo que a introdução, ainda que acessível em sua forma datilografada - e mesmo passível de reprografia - ficou adstrita aos arquivos da biblioteca. Os editores - Daniel Defert, François 
Ewald e Frédéric Gros - da nova edição da Antropologia, então ajuntada da introdução de Foucault, justificam a sua publicação, aludindo aos fatos de que já havia a ampla circulação desse manuscrito (o que é fundamental para respeitar a regra testamentária de não se fazer publicações póstumas) e pelas confusóes interpretativas geradas pela má qualidade de digitação e reprodução do material. Trata-se também, partindo dessa abertura produzida pelo pensamento foucaultiano, de relançar a questão sobre o homem e, assim, pensar de outra perspectiva a antropologia. Ou melhor, esse número de Rue Descartes tem como élan uma atitude frente ao presente, a isto que somos enquanto singularidade histórica. É por isso herdeira, tanto de Foucault, quanto de Kant, fazendo com que tenhamos não só a coragem necessária, mas o dever de pensarmos a atualidade e desenvolvermos uma espécie de cuidado com o qual possamos nos ocupar com as práticas que nos sujeitam, que nos constituem enquanto objeto de conhecimento, mas também que possamos nos constituir enquanto sujeitos, cuja conduta seja diferente das formas de governo que nos perpassam. É certo que, nascida da necessidade de promover novos encontros, Rue Descartes, frente ao diagnóstico foucaultiano do desaparecimento, que abre o pensamento para a história, no qual estamos e não nos permite mais dar uma resposta final à pergunta kantiana - $O$ que é o homem? -, não busca uma essência a-histórica, na qual se revelaria a verdade do humano, mas aceita essa abertura, afirmando o pensar como um eterno retorno a nós mesmos, como reativação das forças, como reavivação da vida em sua finitude, reconhecendo que o esclarecimento náo faz ver um fora do que somos, mas é a tentativa de ampliarmos as forças em jogo, mostrando que aquelas que nos constituem não são necessárias e evidentes. Por isso, a liberdade só pode ocorrer num jogo estratégico no qual nos voltamos para nós mesmos indefinidamente, para sermos diferentes, como a criança que todos os dias constrói na areia o castelo, sem a tristeza pelo fato de que o mesmo possa ser desmanchado pela água do mar.

\section{SOBRE A MARGINALIDADE DE UM TEXTO}

Sabemos que a tradução e a introdução do texto kantiano foram feitas por Foucault nos anos sessenta e só publicadas cinco anos atrás e, por isso, nos perguntamos: por que um texto permanece marginal, durante tanto tempo? Tratar-se-ia de um texto menor, quando olhamos a Introdução em relação ao conjunto da obra foucaultiana e quando olhamos a Antropologia do ponto de 
vista pragmático, com respeito ao conjunto da obra kantiana? O que define a menoridade de um texto?

Esse número de Rue Descartes resiste à premissa corrente que relaciona menoridade e marginalidade ao erro e à irracionalidade, na medida em que está em consonância com o pensamento foucaultiano, quando este afirma, no final de $A$ arqueologia do saber (1969), o árduo trabalho da análise para enfatizar que a massa documental estudada é a materialização de relações de forças, efeito de relaçóes de poder e não mera narrativa ou representação de fatos passados. Ou seja, o estatuto de cientificidade ou de verdadeiro pretendido ou assumido por alguns discursos tem sua formação na imposição, subjugação de determinadas práticas discursivas em relação a outras. Dessa forma, para Foucault, o saber é definido como campo estratégico de relaçóes de poder, não mero reflexo de um estado de coisas ou comentário que busca reproduzir uma essência já constituída e, por isso, é inclusive uma ferramenta perigosa que impóe determinada ordem ao sujeitar outros saberes. Nesse sentido, Rue Descartes afirma ser o saber a inscrição das lutas, marcas dos conflitos entre os homens. Assim, a revista não é alheia ao fato de que os duplos menoridade/ maioridade e centralidade/marginalidade são efeitos dos jogos entre saber e poder, e que "[...] a 'verdade' está circularmente ligada a sistemas de poder, que a produzem e apoiam, e a efeitos de poder que ela induz e que a reproduzem" (FOUCAULT, 1998, p. 14). Nela, o saber não é tratado meramente como um conjunto de signos que simplesmente transmitem informaçôes ou são fontes de esclarecimento de significaçôes primeiras, cuja condição de possibilidade é um sujeito externo (expectador) que assegura essas relaçóes, mas são arranjos de práticas coletivas que determinam significados, sentidos, objetos, sujeitos e explicaçóes locais inerentes a essas coletividades. É pelo entendimento de que as problematizaçóes e as interrogaçóes surgem dessas práticas locais, dessas configuraçóes descompassadas e belicosas, desses textos marginais e menores, que Rue Descartes concede à Introdução e a tradução de Foucault um lugar central. E é justamente por esse deslocamento que o número da revista lança nova luz ao problema do ser humano e reaviva o pensamento filosófico, ao abrir novas possibilidades de interpretar as filosofias de Kant e de Foucault.

\section{UMA REVISTA INTERNACIONAL COMO ENCONTRO DE ONZE VOZES}

Os textos constituintes da revista nos mostram que a Introdução de Foucault e a Antropologia de Kant ainda são cruciais para pensarmos problemas 
que determinam fundamentalmente aquilo que somos. As posiçóes dos autores da revista revelam que a problemática do ser humano exige, hoje, perspectivas que fujam da relação considerada necessária, pela modernidade, entre uma razão hipertrofiada emancipatória e o progresso, da qual a pergunta pela essência do homem é devedora. Nesse sentido, a revista, ao ser escrita por autores de sete países (Portugal, Itália, Alemanha, Brasil, Estados Unidos, França e Espanha), nos apresenta uma multiplicidade de pensamentos que rompem com a velha maneira eurocêntrica de abordar o problema antropológico, para a qual os baixos trópicos e o leste do globo eram sinônimos de subdesenvolvimento e fraqueza intelectual, incorporando, não sem um gosto amargo e um riso amarelo, aqueles que ainda querem conservar uma "pureza" filosófica, valores "bárbaros" à problemática humana. É esse espírito que dá vida a esse número de Rue Descartes, ao flexionar os limites geográficos que separam seus autores, sem negar suas diferenças, fazendo dela uma revista internacional.

De certo modo, pode-se afirmar que o ápice do dossiê se dá no diálogo entre Étienne Balibar e Gunter Gebauer, acerca da condição humana. Eles estão entre aqueles raros filósofos que atualmente não temem utilizar a palavra antropologia, mas não o fazem de maneira ingênua; ao contrário, discutem as possibilidades do pensamento sobre o ser humano, tendo em vista que nossa maneira de pensar já náo pode ser sistematizada a partir de um sentido doado por um sujeito a priori. Dessa forma, cada qual à sua maneira, postulam uma antropologia filosófica e uma antropologia histórica redimensionando a problemática do humano, com base na provocação foucaultiana sobre a qual assenta o estatuto atual para se pensar o humano, tendo como apoios fundamentais autores como Marx e Wittgenstein, além de um interesse nas ciências humanas.

Pode-se afirmar que desse encontro dialogal giram os demais textos do dossiê: Diogo Sardinha, em Diferença entre antropologia pragmática e antropologia metafísica, mostra a diferença - e consequências para o que somos - entre uma possibilidade de pensamento que busca saber o que é o ser humano (antropologia metafísica) e outra que busca pensar o que ele $f a z$ de si-mesmo (antropologia pragmática); Roberto Nigro, em $O$ estardalhaço da crítica do sujeito fundador no despertar do sono antropológico, afirma que a crítica da questão antropológica promove uma abertura para o pensamento, na qual a subjetividade deixa de ser reduzida a um sujeito fundador para ser pensada como efeito de práticas historicamente constituídas; Guilherme Castelo Branco, em A presença de Descartes e de Kant na obra de Foucault, 
demonstra como, em momentos diferentes da sua obra, Foucault opóe Kant a Descartes, a fim de problematizar a nossa atualidade; Marco Díaz Marsá, em $A$ ideia de sensibilidade transcendental na introdução à antropologia de $K a n t$, redimensiona a questão antropológica, ao problematizar, com base principalmente na Introdução de Foucault, a relação entre o sensível e o racional, na constituição do humano; JörgVolbers, em Michel Foucault, filósofo da liberdade? Sobre sua leitura de Kant na Introdução à antropologia, ressalta que, na Introdução de Foucault, a crítica do sujeito se constitui como uma forma específica de problematização da liberdade, que, aproximando-a do texto kantiano, Volbers chama de liberdade pragmática; Márcio Alves da Fonseca e Salma Tannus Muchail, em A tese complementar na trajetória de Foucault, nos mostram como um texto considerado menor e de juventude, sem afirmar uma continuidade ingênua ou uma ruptura total, é hodierno e, nisso, é mais uma ferramenta para podermos lançar nova luz nos problemas produzidos pelo pensamento foucaultiano e naquilo que somos enquanto atualidade; Mathieu Potte-Bonneville, em Ao sujeito terreno ${ }^{3}[$ Au sujet $d u$ terrain]-Subjetivação e Etnologia, tenta compreender a relação entre Filosofia e Etnografia, convidando aquela para vir ao campo desta e, assim, problematizar práticas sociais e culturais de subjetivação; Gabriel Rockhill, em Como pensar o presente? Da ontologia da atualidade à ontologia sem o ser, problematiza a relação entre história e ontologia a partir da noção de "ontologia do presente", cunhada por Foucault, nos seus últimos textos.

De sete países, esses onze autores fazem de Rue Descartes uma forma específica de encontro - um bom encontro. A sua especificidade - ser bom se constitui no fato de a aliança ser forjada na atitude de resistência dos autores a todos os tipos de práticas intoleráveis que nos perpassam constantemente, ou seja, um encontro forjado no combate pela liberdade, contra as injustiças, contra a miséria. É essa tensão política que talvez propicie ao leitor avaliar, perceber, sentir em si, ao entrar em encontro com a revista, as forças, os afetos que estão em gládio nele mesmo e, dessa forma, promover o que Foucault chamou de práticas de si.

\footnotetext{
${ }^{3}$ Há uma ambiguidade com a qual o autor joga acirradamente: a primeira parte do título sugere que o tema do campo, próprio das pesquisas etnológicas, aflore aqui como tema, posto que a provocação inicial parte justamente de alguns etnólogos (Michel Agier e Ann Stoller, da EHESS - Paris), assim como uma espécie de convocatória pela qual se exige, de modo náo menos provocativo, que a filosofia se volte a pensar o sujeito encarnado e situado, isto é, não de forma abstrata e "desconectada" da realidade empírica.
} 


\section{A EXPORTAÇÁO DE IDEIAS COMO PRÁTICA DE LIBERDADE}

É, principalmente, no final dos anos setenta e início dos oitenta do século passado que Foucault problematizou as práticas de si. Estas se constituem sempre vinculadas a práticas de poder e saber e designam o indivíduo enquanto posiçóes variáveis na trama destas, que são múltiplas e flexíveis. Logo, o indivíduo pode entender-se e constituir-se como sujeito que participa de um jogo no qual sua experiência pode modificá-lo, criá-lo, limitálo e, nisto, também, criar-se, modificar-se. Suas escolhas e reaçóes são sempre condicionadas no movimento estratégico em que ele se constitui como sujeito, no caso das práticas de si, e é tornado objeto em relação às outras práticas. Dessa forma, as escolhas referem-se aos limites constituídos pelas práticas de saber e poder, problematizando-os e mostrando-os em sua contingência; e, com isso, tornando-os pontos de instabilidade, nos quais sua legitimidade é questionada, permitindo, assim, uma intensificação das forças, na medida em que novas relaçôes, escolhas e experiências se tornam possíveis. As práticas de si assumem os riscos de decisôes únicas, pois se trata justamente de desenfeitiçar, sacudir e deslegitimar os limites naturalizados, historicizandoos, movimentando-os, denunciando-os como efeitos de práticas de poder e saber. Elas traduzem transgressôes pensadas como dobras de subjetivação, nem simplesmente intrínsecas, nem simplesmente extrínsecas às práticas que as viabilizaram, porque é esse jogo que é instabilizado, provocando a sua modificação, sua renovação e não sua destruição total. São nesses desafios entre limite e transgressão que se constitui o si mesmo como dobra do poder, ou seja, como espaço estratégico no qual ocorrem as escolhas e as resistências frente ao governo que faz do indivíduo e da vida objeto de poder. Desse modo, as práticas de si definem uma ética do cuidado de si como cuidado desse espaço estratégico (si mesmo) contra as "[...] formas atuais de sujeição, uma que consiste em nos individualizar de acordo com as exigências do poder, outra que consiste em ligar cada indivíduo a uma identidade sabida e conhecida, bem determinada de uma vez por todas" (DELEUZE, 2005, p. 113). As práticas de si constituem a luta contra as práticas de sujeição que perpassam a sociedade e a nós mesmos e o esforço para inverter o seu sentido, se apropriando delas, configurando um cuidado da força. É no si mesmo em que a dobra se dá, não como apego pelo poder, mas como governo de si no sentido de condução da própria vida, como atividade de cultivo de si mesmo, como atualização e proliferação das relaçóes de forças e, portanto, de intensificação da vida. 
É por esse legado deixado pelo autor de As palavras e as coisas, e por lutar pela liberdade, que o Collège International de Philosophie insistiu pela difusão da Introdução foucaultiana à Antropologia de Kant, culminando nesse número de Rue Descartes com a parceria da Fundação Calouste Gulbenkian, responsável pelas imagens estampadas na revista. Os autores escolhidos também o foram por causa da sua longa trajetória de problematização e propagação dessa herança do autor francês. Percebemos nesse esforço de instituições e de indivíduos o questionamento de como a liberdade pode realizar-se, náo como um além do poder, mas como resistência e torção deste e, por isso, ampliando os espaços de luta e possibilitando a criação de novas formas de subjetivação, de sorte a dar um sentido a nós mesmos, como desprendimento e criação constante. São essas açóes corajosas - quando perguntam o que, nas relaçôes atuais de poder, precisa ser mudado e quais os perigos que elas renovam constantemente - que afirmam a liberdade como um exercício constante de modificação de tudo aquilo que tenha pretensão de evidência absoluta, pois, seja no campo ético ou político, implicam críticas das estratégias postas pelo nosso presente, visando à sua transformação. Por conseguinte, referem-se a um cuidado com a atualidade, no qual não se trata de conjurá-la como uma situação de completa sujeição, nem glorificá-la como situação de liberação, mas um atentar-se ao poder, para que não ocorra a solidificação de uma forma de domínio a qual limite as possibilidades de produção de novas formas de relaçóes, ou melhor, de novas formas de vida. Parece-nos que é exatamente esse o esforço que deu vida e é movimentado por Rue Descartes.

\section{REFERÊNCIAS}

DELEUZE, Gilles. Foucault. Trad. Claudia Sant'Anna Martins, revisão da tradução Renato Ribeiro. 5. ed. São Paulo: Brasiliense, 2005.

FOUCAULT, Michel. As Palavras e as Coisas. Trad. de Salma Tannus Muchail. 6. ed. São Paulo: Martins Fontes, 1992.

. Verdade e Poder. In: Microfisica do poder. Org. e Trad. de Roberto Machado. 13. ed. Rio de Janeiro: Graal, 1998.

SARDINHA, Diogo (Org.). Revue Rue Descartes (dossiê Kant/Michel Foucault et le renouveau de la philosophie antropologique), $\mathrm{n}^{\circ}$ 75: 1-125, 2012/2013.

Recebido em: 05.01.2013

Aceito em: 29.04.2013 